\title{
Los beneficios económicos del proceso de integración centroamericana
}

\author{
José ANDrÉs Oliva \\ Departamento de Economía \\ Universidad Centroamericana (UCA) \\ San Salvador
}

\begin{abstract}
Currently, the transcendence of the economical integration process is unknown in the Central American region. The theoretical and practical fundaments of the Central American economical integration are quite weak. The author of this essay seeks to establish a new theoretical basis in order to strengthen the economical integration process.
\end{abstract}

Actualmente, Centroamérica toma decisiones en el marco de dos grandes fuerzas mundiales: el libre comercio global o multilateralismo y la integración en bloques o el regionalismo global. Hoy en día, el segundo parece sobrepasar al primero, desencadenando nuevos posicionamientos de las potencias mundiales en sus áreas de influencia.

Vemos por una parte, una tendencia hacia el regionalismo, reflejo de ello, fue el GATT (Acuerdo General sobre Tarifas y Comercio), transformado en la OMC (Organización Mundial del Comercio), recibió el doble de notificaciones de acuerdos regionales durante 1990-1995 de lo que recibió durante los años 1970 y $1990^{1}$. A esto se le conoce como nuevo regionalismo ${ }^{2}$. Luego, en este sentido, los Estados Unidos desistió de apoyar

Los beneficios económicos del proceso de integración centroamericana 
un multilateralismo global y ha hecho viraje en su política de comercio internacional, firmando el TLCAN (Tratado de Libre Comercio de América de Norte) en enero de 1996, y propiciando el ALCA (Área de Libre Comercio de las Américas) cuya culminación se espera en el año 2005. Asimismo, anunció en la declaración de Bogor en el 1994, un compromiso de crear una zona de libre comercio para el 2010 entre Asia y América, del cual participarían países como México, Chile y Australia. Es así que surge la pregunta: ¿La integración centroamericana será absorbida por estos procesos?.

Por otra parte, la Unión Europea concentra toda su energía en el proceso de su nueva ampliación, incluyendo a países de Este europeo, que alguna vez fueron zona de influencia de la ex Unión Soviética, pasando de 15 a 28 miembros.

Se sostiene que el multilateralismo es una posibilidad viable y deseable, facilitada por este auge del regionalismo, provocado por la disminución de las partes involucradas en las negociaciones, que con lleve a un gran acuerdo global de libre comercio auspiciado por la OMC.

Partiendo de estos fenómenos, se produce en el ambiente una falta de conciencia del sentido económico de la integración en Centroamérica, vacío fortalecido por el choque entre el regionalismo y el multilateralismo.

Actualmente las potencialidades de la integración, están en el centro de nuestra política exterior, la cual, por una parte, intenta profundizar el proceso de integración económica perfeccionando la unión aduanera, adquiriendo el compromiso de desmantelar las aduanas intraregionales, y por otra firma un Tratado de Libre Comercio con los Estados Unidos (CAFTA).

Existe una expectativa sobre cuál es el rumbo que tomarán las negociaciones de política comercial en Centroamérica, cuya visión preponderante de política establece que la integración facilitaría los procesos multilaterales de comercio, lo que puede repercutir en la reducción de la profundidad de la integración en el largo plazo, alimentando una dispersión de esfuerzos por crearla.

De lo expuesto surgen algunas preguntas. ¿Es el modelo de integración económica una teoría de desarrollo efectiva para disminuir los niveles de pobreza en las economías del tercer mundo? En términos más concretos, si los países del Este de Europa se integran a la Unión Europea o los 
países de América Latina ratifican el ALCA, ¿Podrían estas naciones desarrollarse en plenitud? ¿Cuáles son los factores claves para que Centroamérica se Desarrolle en este contexto?.

Para dibujar algunas respuestas, estructuraré este contenido en tres partes. La primera abordara los principios teóricos sobre los que se sustentan estas dos fuerzas paralelas, introduciendo las razones teóricas para la integración en países subdesarrollados. Luego, en la segunda parte, se ubicaran las observaciones empíricas en Centroamérica con el apoyo de índices de medición y en la tercera, se enumeraran las conclusiones.

\section{Razones teóricas para la integración económica en países subdesarrollados}

Para sostener la integración en Centroamérica, se debe partir de que estamos ante un conjunto de países subdesarrollados y que la integración puede incidir en ese subdesarrollo. Sus características más generales son las siguientes: el comercio extra regional es relativamente más grande que el comercio intraregional, experimentan grandes y crecientes déficits en la cuenta comercial, exportan productos primarios de poco valor agregado y la mayoría de los recursos están organizados alrededor de esos productos, son grandes importadores de bienes intermedios y de capital. Por otra parte, esos bienes intermedios son los que posibilitan la producción de bienes en la economía, incluso para la exportación, desembocando en pocos encadenamientos con los otros sectores. Estos bienes importados se pueden dividir en dos grupos: importaciones para el mantenimiento de la producción (bienes de capital y bienes intermedios) e importaciones para el mantenimiento del consumo (bienes finales). Estas características conducen a pensar que el comercio exterior es uno de los factores que de una manera contundente determinan el desarrollo o el subdesarrollo de los pueblos ${ }^{3}$.

La integración podría contribuir a generar las condiciones, para producir algunos bienes intermedios y de capital de una manera eficiente y competitiva. $\mathrm{Y}$ al mismo tiempo, posibilitar un tejido productivo que transcienda hacia otros productos con un mayor valor agregado, sostenidos en un mercado interno más grande, haciendo crecer las economías.

En general las ventajas del comercio internacional para los países subdesarrollados, se materializan, casi exclusivamente, en ventajas absolutas o comparativas, ocasionadas por una mayor o menor abundancia relativa de factores de producción, como consecuencia de sus condiciones ambientales, podemos citar como ejemplos a Venezuela con el petróleo, 
Chile con el cobre y ha Centroamérica con el café, recientemente casi sustituido por las Maquilas de la Industria de la Confección.

La teoría más clásica de las uniones aduaneras, fue introducida por Jacob Viner (1950), en su libro "the Custom Union Issue", publicado en 1950. Viner creó mediante un modelo, inspirado en David Ricardo, de equilibrio parcial de estática comparativa, dos ideas fundamentales: Creación de comercio y desviación de comercio.

La creación de comercio es el flujo de bienes, productos o servicios que se produce cuando se cambia la fuente de abastecimiento de una economía de costos mayores a otra de costos menores, en otras palabras, pasan a una fuente más eficiente en la producción y en el uso de los recursos. Por lo general, se concibe cuando todas las importaciones más caras son sustituidas por importaciones más baratas provenientes del exterior de la unión. Otra posibilidad es que el productor eficiente se encuentre dentro de la unión con lo que se crearía comercio pero en el interior.

La desviación de comercio es el flujo de bienes, productos o servicios, que se produce cuando se cambia la fuente de abastecimiento de una economía de costos menores a otra de costos mayores. Es decir, pasan a una fuente ineficiente en la producción y en el uso de los recursos. Son por lo general, todas las importaciones más baratas de países externos de la unión que son sustituidas por productos de la unión más caros.

Desde su visión se puede sostener que para países subdesarrollados la integración no contiene ninguna ventaja, lo únicamente relevante es la asignación eficiente de los recursos. Las uniones aduaneras son siempre viables, si y solamente si, la creación de comercio superara a la desviación del comercio. Ya que estos países no producen eficientemente determinados bienes que son necesarios para el mantenimiento del consumo y de la producción de las economías. Y si se aumentara la protección con una unión aduanera, la mayor protección significaría la ruptura del canal que permite la entrada a estos bienes.

Para él, el efecto de creación de comercio mejora la asignación de recursos dentro de la unión y el bienestar de la economía internacional, fomenta la especialización y la explotación de las ventajas comparativas, además mejora la situación de los países socios porque crea más demanda para sus productos. El efecto de la desviación de comercio reduce el bienestar, y perjudica a productores externos más eficientes en beneficio de productores internos más ineficientes. 
Ahora bien, una de las conclusiones del análisis de Viner es que una unión aduanera puede tener mejores beneficios que el libre comercio, o un tratado de libre comercio, dependiendo de las características de la unión y postuló, que si se dan todos los factores necesarios para que "la creación de comercio supere a la desviación de comercio, la unión aduanera puede ser más beneficiosa"4. Es decir, las ventajas de las uniones aduaneras dependen de las fuerza relativa que predomine de los dos efectos, fundamentalmente que conduzcan a la asignación mas eficiente de los recursos.

Según Viner, es más factible que la creación de comercio sea mayor que la desviación de comercio, cuando son muchos los países que se integren, cuanto menor sea el nivel medio de las tarifas arancelarias antes de formar la unión y mayor sea el grado de competitividad entre las economías.

Esta percepción de las cosas fue fortalecida con la introducción del modelo Hecksher-Ohlin, que establece que la razón fundamental que causa los flujos de comercio es la diferencia relativa de factores de producción y el acervo de recursos naturales.

Es así como, los argumentos del análisis de la creación y desviación de comercio no ayudan a dilucidar ventajas económicas de la integración en países subdesarrollados.

No obstante, existen otros especialistas que brindaron un robusto marco teórico a la integración en países subdesarrollados. Estos fueron los estructuralistas: Prebisch (1950 y 1959), Singer (1950), Perroux (1957), Myrdal (1957), Cooper y Massell (1965). Ellos elaboraron el primer esfuerzo teórico en debatir la idea de la ventaja comparativa.

También criticaron el sistema internacional de comercio de aquel entonces sosteniendo que el problema del subdesarrollo consistía, en términos generales, ha que las naciones subdesarrolladas intercambian sus productos primarios de poco valor por productos de gran valor agregado, como bienes de capital e intermedios con países más desarrollados, provocando un deterioro sistemático de los términos de intercambio, conduciendo a una distribución inequitativa de los beneficios del comercio mundial entre países que difieren en sus niveles de desarrollo. La anterior afirmación es tan histórica como actual.

Hay factores distintos a los descritos por Viner, que entran en juego cuando se ponen en contacto dos economías, estos son los efectos 
dinámicos. Estos efectos son de carácter microeconómico, son más difíciles de medir y sintetizar. Son observados con otros instrumentos analíticos, los cuales abandonan todos aquellos supuestos del modelo de Viner de equilibrio parcial de naturaleza estática, pasando a modelos de equilibrio general de naturaleza dinámica. Su análisis no es tan uniforme como los efectos estáticos.

Son estos efectos dinámicos los que renuevan el sentido de la integración en países subdesarrollados y son los mismos, que según la literatura, hicieron crecer a las grandes estado-federaciones del mundo, como Estados Unidos y Alemania, hace muchos años atrás.

La visión neo estructuralista más repetida en la literatura sostiene que la integración puede tener un impacto en la estructura productiva de los países, provocando un aumento de la productividad de los factores desencadenado por estos efectos dinámicos. También puede haber un impacto positivo si en algún caso, un socio de la unión pueda ser un productor sustituto más eficiente y pueda acrecentar su escala y reducir costos.

Por lo tanto las estrategias de integración en países subdesarrollados, como un primer aspecto, puede incidir en las estructuras empresariales, a través de sus efectos dinámicos, generando condiciones para diminuir la dependencia de ciertos bienes que solamente se pueden producir a gran escala y para ser luego, incluso exportados.

Existe un segundo aspecto importante. Según la teoría reciente del comercio internacional no sólo las diferencias entre las economías y sus empresas dan lugar a flujos comerciales sino también sus semejanzas. A partir de ello se establecen dos posibles tipos de comercio: el interindustrial y el intraindustrial. Este último es más frecuente en esquemas de integración.

En el mundo, el comercio intraindustruial se observa entre países desarrollados y más aún en el Mercado único Europeo, donde todo el engranaje que se ha montado en el proceso de Integración lo ha alimentado y posibilitado, contribuyendo a su éxito.

El comercio intraindustrial es uno de los fenómenos recientes del comercio internacional, se trata del intercambio simultáneo del mismo tipo de bienes, dentro de la misma industria. Las ventajas de este tipo de comercio provienen de la competencia y la ampliación del mercado, potenciado por acuerdos de integración. El comercio Interindustrial es el 
concepto contrario, es el intercambio de diferentes tipos de bienes o productos.

Existen estudios que mencionan que el comercio internacional de Centroamérica está sustentado en ventajas absolutas, como él de Óscar Cabrera (2002) y otros que establecen la importancia económica del comercio intraindustrial, para la economía centroamericana, como los realizados por Luis René Cáceres (1992) y Vulmer Thomas (2003). Estos estudios también mencionan el debilitamiento que pueden sufrir los poderes monopolísticos y oligopolísticos con la integración.

Desde esta perspectiva en conjunto, la desviación de comercio pudiera ser el efecto deseado, y la resignación más eficiente de los recursos tener una importancia relativa. Este era el espíritu del Mercado Común Centroamericano durante la década de los sesenta, impregnado de la estrategia de industrialización sustitutiva de importaciones, en donde el objetivo era proteger una industria naciente y la desviación de comercio conllevaría efectos dinámicos ventajosos en el largo plazo, conduciendo a uno de los momentos de mayor crecimiento en Centroamérica.

La característica que diferencia la actualidad con aquellos esfuerzos es que el objetivo último para cambiar las estructuras mediante la integración ahora es la "competencia" interna en Centroamérica, dentro de un marco institucional. Esta competencia puede reducir la concentración de recursos en empresas que estén explotando economías de escala monopolísticamente. Por esta razón, sería necesaria una política antimonopolios a nivel regional, que provenga de la estructura institucional, que en esquemas integracionistas es más factible construir y concertar.

En este sentido, otro punto de visita es él del economista François Perroux, que critica la integración por los efectos negativos que tiene, que desde 1967, postuló que "en una integración de dos territorios desiguales y de dos economías desiguales, la población del país más rico debe aceptar una política de distribución y de compensación que favorezca el desarrollo del socio más débil"s. Para él, el objeto de la integración radica en incidir en el desarrollo de las estructuras de los aparatos productivos, de tal manera que pueda generarse una economía más amplia que esté al servicio de toda la población. Estos principios son en los que se basan, los fondos estructurales que la Unión Europea otorga a sus miembros menos desarrollados.

Para Perroux, la simple eliminación de los obstáculos al intercambio entre espacios heterogéneos dominados por monopolios y oligopolios, dotados de 
súper estructuras concebidas por los gobiernos, no tiene ninguna posibilidad de poner al servicio de la población el aparato productivo, por esta razón Perroux opina que la integración debe ir acompañada de poderes compensadores, que provengan de institucionales comunes.

Por lo tanto, podemos decir que la Integración Económica no es un proceso armonioso hacia la eficiencia y eficacia, los recursos se pueden dirigir hacia las zonas geográficas de mayor desarrollo provocando ajustes costos. En otras palabras, el bienestar solamente aumentará si hay compensaciones, que sean mayores a los perjuicios experimentados por los perdedores.

Asimismo, es difícil que la Integración Económica implique iguales beneficios para todos, es más probable que en el corto plazo los beneficios netos sean desfavorables, situación que cambiaría en el largo plazo.

Vemos pues que hay otros economistas que observan que este fenómeno posee un proceso de ajuste que implica algunos problemas y por lo cual, es importante no perder de visita los aspectos más importantes de la estructura organizativa e institucional de la integración, ya que ésta no es una panacea, implica ajustes costos y para su adecuada gestión necesita inexorablemente de un marco jurídico e institucional que le dé dirección.

Según la teoría de la integración, la envergadura de la competencia es la que produce la diferenciación del producto o un progreso tecnológico porque impulsa la innovación.

En el comercio intraindustrial los conceptos tradicionales de ventaja absoluta y relativa tienen poca o nula aplicación, ya que no está motivado por la abundancia relativa de algún factor de producción o en la productividad de determinados bienes.

El fenómeno en la actualidad no se conoce a plenitud. Sus modelos son de competencia imperfecta, en los que se analizan fenómenos de diferenciación del producto, abandonando muchos supuestos restrictivos, como la competencia perfecta, los rendimientos constantes a escala y productos homogéneos de naturaleza estática.

También, al poner en contacto dos economías, si los bienes que se comercian son similares o no, tiene un peso importante, ya que las exigencias de ajuste son diferentes, la Interindustrialidad, implica el cierre total o parcial de una industria o rama de actividad en uno de los países, en cambio, la Intraindustrialidad implica la expansión de la misma rama de actividad en las dos economías y más aún si las técnicas de producción 
son similares, las estructuras económicas tenderán a aproximarse y los problemas de ajuste serán menores. En este sentido es útil distinguir entre la creación de comercio de tipo intraindustrial o interindustrial.

En otras palabras, el comercio interindustrial provoca ajustes más dolorosos, debido a que los movimientos de los recursos son de mayor envergadura, lo que requiere de tiempo y de esfuerzos. En el comercio Intraindustrial el ajuste tiene menores implicaciones, algunas líneas de producción se contraen, pero otras de la misma industria se expanden y la industria en el otro país no desaparece. Además diversifica el comercio.

Esto nos lleva a la comprensión del hecho ejemplarizante que $e l$ comercio intracentroamericano es de mayor valor agregado que el comercio con el resto del mundo, aunque esté sea de mayor volumen, y el comercio intraindustrial, está más concentrado en el comercio intracentroamericano ${ }^{6}$. En otras palabras, internacionalmente nuestras exportaciones se concentran en pocas industrias, concentrando una gran cantidad de recursos de la economía en esos sectores, lo que es doloroso ante choques externos, incidiendo en poca diversificación del comercio.

En este mismo sentido, Miroslav Jovanovic, menciona: "El comercio entre países que tienen diferentes costos de producción para similares productos, con diferentes dotaciones de factores de producción, con diferentes preferencias de los consumidores, se caracteriza por ser de tipo interindustrial, mientras el comercio entre países con costos similares de producción de similares productos, con similar dotación de factores de producción y similares preferencias del consumidor, se caracterizan por ser de tipo intraindustrial"'.

En el párrafo anterior se comparan dos grupos de países. Entre países de desarrollo desigual, el comercio tiende a ser interindustrial, mientras que entre países cuyo desarrollo es similar, el comercio tiende a ser intraindustrial. Otro aspecto a valorar es que la estructura en el intercambio es diferente. Esta puede ser complementaria o competitiva respectivamente.

Otra ventaja del comercio Interindustrial es que posibilita aumentos en los incentivos de la competencia la cual genera procesos de diferenciación del producto.

También es posible distinguir el tipo de diferenciación dentro del comercio intraindustrial, que puede ser de carácter horizontal o vertical. Comercio vertical corresponde al intercambio de productos diferenciados en la calidad. El comercio horizontal corresponde a una diferenciación 
del diseño o en la presentación. Si tienen un precio unitario parecido se consideran horizontales partiendo del supuesto que las diferencias en el precio reflejen diferentes niveles de calidad.

Los bienes intraindustriales de diferenciación horizontal se pueden considerar sustitutos cercanos. Según la teoría los efectos del comercio de sustitutos cercanos son aún más suaves. Ya que para una empresa ofrecer un bien con mayor calidad es más difícil que cambiarle la presentación o el diseño.

Cuando los bienes se comercian en ambas direcciones, las empresas de esas economías recurren a la estrategia de diferenciar el producto con mayor variedad o mayor calidad. Y cuando estamos hablando de un mercado integrado, con consumidores de gustos similares, esto puede ser una ventaja. Las empresas emprenden la comercialización de nuevos productos con determinadas cualidades que los diferencian y amplían la variedad de su oferta. Estos productos pueden llegar a consumidores más específicos con gustos y preferencias especificas. Ello diversifica la producción y aumenta el valor agregado de los productos que se comercializan y los consumidores elevan su bienestar.

Es importante considerar las preferencias del consumidor, en ocasiones pueden preferir la variedad a la cantidad y esto repercute en mayores beneficios, diferentes a la explotación de economías de escala, las que incluso puedan perder protagonismo, ya que explotan la producción de bienes que son estándar, lo que no aumenta la variedad.

Entre otros argumentos a favor de la integración en bloques, puede ser el referido a los costos de transporte, ya que las economías de escala no se pueden desarrollar por pérdidas en la competitividad en mercados muy lejanos debido a los grandes costos de transporte. (Vulmer Thomas) ${ }^{8}$. En un mercado regional integrado posiblemente los costos de transporte sean menores y las economías de escala más factibles.

\section{La integración económica centroamericana}

Esté apartado estará dividido en dos partes. En la primera se realizara un diagnóstico económico de la integración económica, y una aproximación al análisis de los efectos de creación y desviación de comercio en Centroamérica. Luego, se ubicó a un análisis de la estructura de los flujos comerciales intraindustriales, en Centroamérica.

Es necesario aclarar, que durante todo el apartado, los datos están expresados en pesos centroamericanos como medida de homogenización 
que equivale a un dólar estadounidense, adicionalmente la información no incluye a la maquila.

En la mayoría de gráficos siguientes podremos ver como se pueden diferenciar dos periodos: antes de 1979 y después. Recordemos que este es el tiempo donde se agudizaron los conflictos armados y la época de la crisis de la deuda externa.

En el gráfico número 1, se observan las variaciones del PIB per cápita de los países centroamericanos, lo que nos da alguna referencia del crecimiento que se ha experimentado en este período. No se pretende indagar en cuáles son los nexos fundamentales entre la integración y el crecimiento, sin embargo, partiendo de la teoría podemos pensar que algún grado de vinculación debe existir. De los datos lo único que es posible inferir, es que en los años en que la Integración Económica tuvo más vigor, el crecimiento también fue más fuerte, ya que en los años sesenta y setenta el crecimiento económico fue más fuerte que en los noventa.

\section{Gráfico No. 1. Variación del Pib Per cápita}



Fuente: Consejo Monetario Centroamericano.

Se ven los dos períodos. El viejo regionalismo, con el modelo de industrialización basada en la sustitución de importaciones, donde había un clima externo que favoreció y posibilitó ese tipo de planteamientos y el del nuevo regionalismo, en un período actual de liberalización de comercio internacional de carácter multilateral con unos agentes externos 
que propician un clima de desarme arancelario de las economías y de globalización.

Es necesario mencionar que, de 1986 a 2002, se ha dado un crecimiento muy acelerado de las exportaciones intraregionales, mayor al experimentado en los años sesenta y setenta, según se aprecia en el gráfico número 2.

Gráfico No.2 Evolución de las exportaciones intraregionales

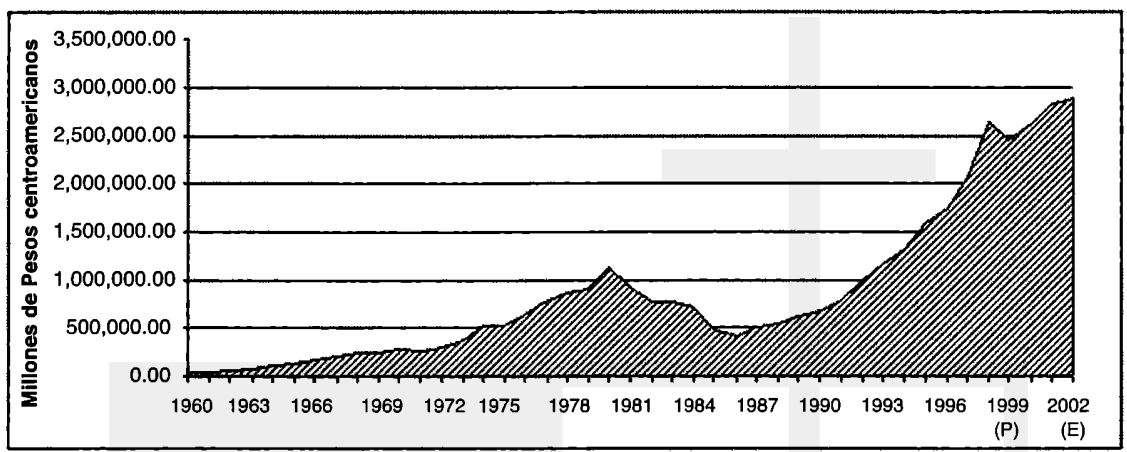

Fuente: Secretaría de Integración Centroamericana. (SIECA)

Como se puede ver en el gráfico No. 3, el comercio intraregional ha pasado por tres momentos: el primero paso de significar el 6.36\% en 1961 a un $24.24 \%$ en 1971 del total de las importaciones. El segundo, es un período de debilitamiento de 1971 llegando a representar un $10.24 \%$ en 1985; y el tercero, de un fortalecimiento, que comenzó en 1986 y finalizó en la actualidad, donde, según estos datos, la participación es de $14.57 \%$.

Gráfico No. 3 Evolución del porcentaje de importaciones intracentroamericanas sobre el total

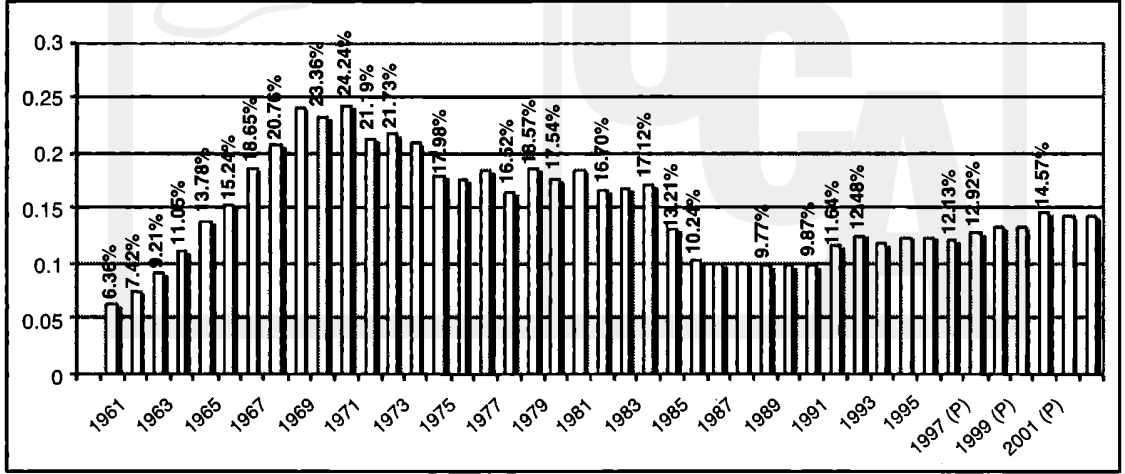

Fuente: Secretaria de Integración Económica Centroamericana. (SIECA) 
Se produjo en las décadas de los setenta y ochenta un aumento más acelerado de las importaciones extraregionales que las regionales. Estas últimas, después de 1969, descendieron hasta 1986, año en que empezaron a aumentar. Sin embargo, la participación en las importaciones totales nunca volvió a representar lo que alcanzaron en 1969.

Resumiendo: es posible postular, que antes de 1979, año en que la integración económica tuvo mas vigor, el crecimiento también fue más fuerte, la participación del comercio intraregional con respecto al comercio exterior creció, sin embargo el comercio interno no creció como lo hizo durante los noventa ${ }^{9}$, después de 1979 , el peso relativo del comercio intracentroamericano y el crecimiento de la economía disminuyeron.

Según los datos del gráfico No. 4, de las exportaciones totales de Centroamérica, el $27.49 \%$ fueron destinadas a países de la región en el 2002. Estas exportaciones se reparten entre los países así: para El Salvador las exportaciones hacia el área centroamericana representaron el $60.57 \%$, lo que ha venido en aumento, para Nicaragua y Guatemala significaron aproximadamente un $39 \%$, le sigue Honduras con un $18.95 \%$ y luego Costa Rica con un $14.26 \%$.

Gráfico No. 4 Participación de las exportaciones intraregionales sobre las exportaciones totales por países

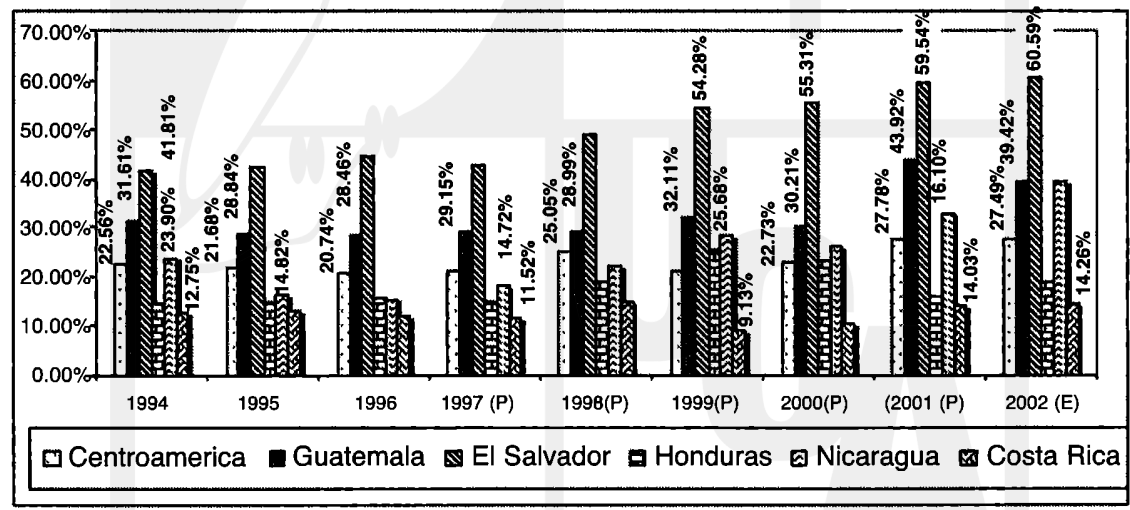

Fuente: Secretaría de Integración Económica Centroamericana. (SIECA)

Por otra parte, desde una perspectiva general, según los datos del 2002, Centroamérica tiene un Producto Interno Bruto (PIB) a precios corrientes de CA $\$ 62,741.8$ millones y exporta al resto del mundo la cantidad de CA $\$ 10,492.48$. Importa de CA $\$ 21,725.3$ millones, de los 
cuales CA $\$ 3$, 087.5 millones son intraregionales y CA $\$ 18,637.8$ millones provienen del resto del mundo ${ }^{10}$.

Según esto, Centroamérica tiene un consumo aparente (PIB menos las exportaciones, más las importaciones) de \$73, 974.62 millones, lo cual el exceso de su PIB, es financiado por transferencias unilaterales o remesas y flujos de capital o financiamiento externo. El coeficiente del PIB menos las exportaciones dividido entre el consumo aparente, (PIB$\mathrm{X} / \mathrm{CA}$ ) del 2002 es de un $70 \%$, las importaciones intraregionales (Mi) significan del consumo aparente un $4.17 \%$, las importaciones extraregionales $(\mathrm{Me})$ significan del consumo aparente un $26.39 \% .{ }^{11}$ Esto ya define los efectos estáticos que una unión aduanera completamente cerrada instantáneamente pudiera tener, existiría una fuerte desviación de comercio provocada por el rompimiento del flujo de importaciones que mantienen la producción y el consumo de las economías centroamericanas. (Ver Gráfico No.5).

\section{Gráfico No.5 Variaciones de los coeficientes de Truman}

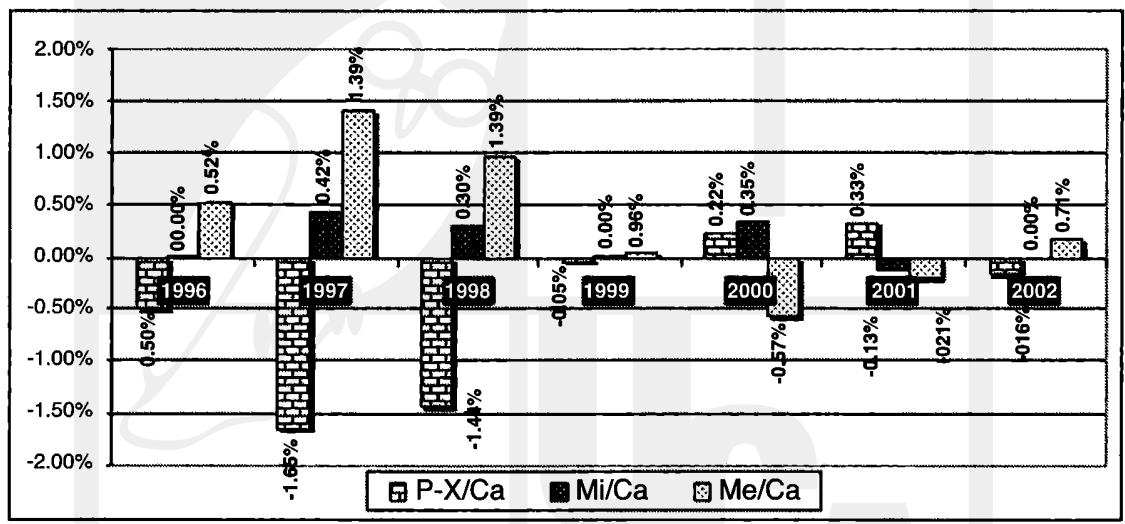

Fuente: Secretaría de Integración Económica Centroamericana. (SIECA)

En el gráfico No.5 se muestran las variaciones anuales de los coeficientes propuestos por Truman para Centroamérica desde 1996. El coeficiente de PIB-X/CA ha variado disminuyéndose en la mayoría de los años, a excepción del 2000 y 2001, esto quiere decir que se ha creado comercio. Podemos ver que durante el período analizado las columnas que representan el coeficiente de importaciones extraregionales sobre consumo aparente $(\mathrm{Me} / \mathrm{CA})$ aumentan más que las columnas que 
representan el coeficiente de importaciones intraregionales sobre consumo aparente (Mi/CA), exceptuando el año 2000. En promedio durante el período estudiando, el $\mathrm{Mi} / \mathrm{CA}$ ha crecido $0.95 \%$ y $\mathrm{Me} / \mathrm{CA}$ ha crecido $2.30 \%$. Esto quiere decir que el comercio que se ha creado es más externo que interno.

Podemos ver cómo, en los años 1997 y 1998 claramente el comercio que se creó está concentrando en el exterior y no en el interior. En otras palabras, la absorción interna se satisface relativamente más con bienes extraregionales que intraregionales. Este comercio interno también tuvo aumentos significativos durante esos años, menores en proporción.

Teóricamente, según esta aproximación, Centroamérica está propensa a crear comercio externo según el concepto tradicional de Viner. Esto quiere decir, que al dejar fuera a los socios de mayor comercio con una posible unión aduanera, con aranceles hipotéticamente altos, situación muy improbable por la cantidad de compromisos internacionales que se han subscrito, con la OMC, la Iniciativa de la Cuenca del Caribe (ICC), etc. existiría una gran desviación de comercio, provocada por en los rubros de bienes donde no tenemos ventajas comparativas, como por ejemplo el Petróleo, bienes informáticos, o bienes de capital. Por otra parte, esta información expresa otro aspecto importante, en el periodo se ha desviado comercio, relativamente poco, durante los años 2000 y 2001, según el gráfico, posiblemente causado por un adverso contexto internacional. Por lo cual es posible decir, que en una proporción mínima, la integración sirve de atenuante en ocasiones de volatilidad de los mercados internacionales, o amortiguadora de choques externos.

Hechos importantes a tener presente es que el proceso de integración también va arrojando perdedores. En cuanto a esto, se presentan en el gráfico No. 6 el valor del saldo comercial intraregional en millones de \$CA por países. Vemos que Honduras es el país con el saldo comercial más desfavorable, le siguen Nicaragua y El Salvador. Guatemala y Costa Rica poseen saldos positivos. 
Gráfico No.6 Saldos intraregionales de comercio por países en pesos centroamericanos

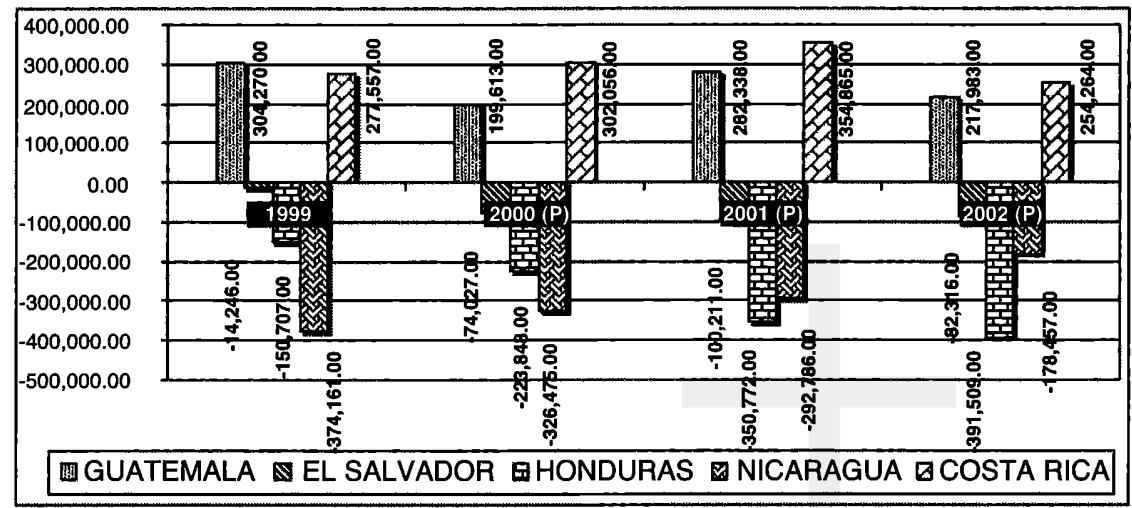

Fuente: Elaboración propia con datos de la SIECA.

Con respecto a las relaciones comerciales con el exterior, el déficit en la cuenta corriente de Centroamérica fue de CA $\$ 11,781,279$ miles en el 2002, los cuales significan de su PIB un $19 \%^{12}$ razón que aumenta año con año. Para la mayoría de los países de C.A. el déficit de la cuenta corriente ha venido aumentando en los últimos años, como puede verse en el Gráfico No.7. El déficit en Nicaragua es el más grande, con $45.90 \%$ de su PIB a precios corrientes. Le sigue Honduras con $33.94 \%$, El Salvador con $19 \%$, Guatemala, con $18.38 \%$ y Costa Rica, con $11.9 \%$ del PIB respectivamente.

Gráfico No.7 Déficit en la cuenta corriente por países como Porcentaje del PIB

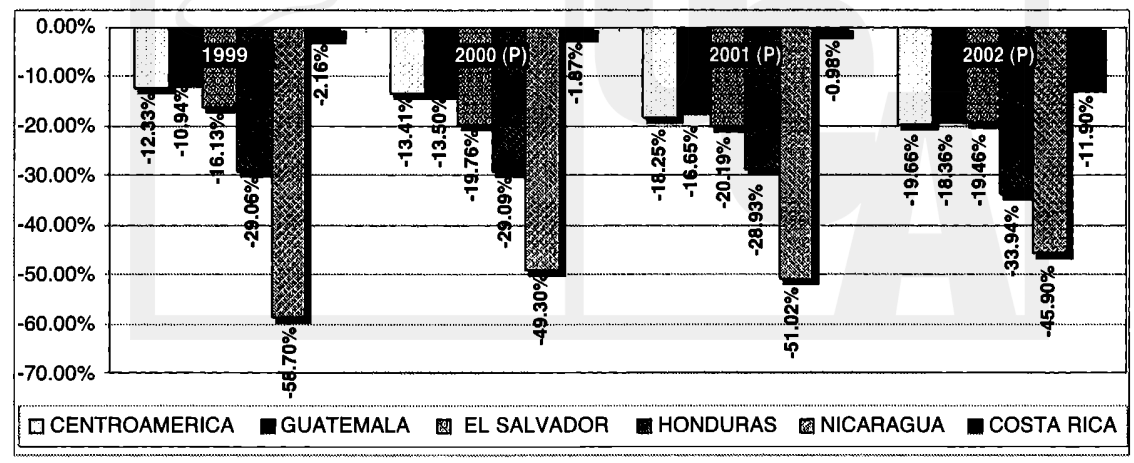

Fuente: Elaboración propia, con datos de la SIECA. 
Centroamérica posee un comercio similar al de los demás países subdesarrollados. Según la información de la SIECA, los principales productos que importa Centroamérica del Resto del mundo son: semiconductores, circuitos y micro estructuras electrónicas, combustibles para vehículos, vehículos y partes de vehículos. Según la misma fuente, los principales productos de exportación son: café oro, cereales, caña de azúcar, algodón, plátanos, aceites pesados (derivados de Petróleo, solamente Guatemala en muy pocas cantidades), piñas tropicales, frijoles, micro estructuras electrónicas (solamente Costa Rica), melones o sandias, prendas de vestir etc. Los bienes exportados se comercian a un precio bajo y las importaciones a un precio alto. Esto empeora la situación de los déficits comerciales.

Las razones teóricas más importantes para potenciar la integración se resumen en que esta puede colaborar a mermar o en todo caso a disminuir estos déficits comerciales. La integración puede llevar a cambios estructurales derivados de los efectos dinámicos potenciados por el comercio intraregional, para ser competitivos en esos rubros, en el largo plazo.

También tiene otros efectos positivos como amortiguar los choques externos y diversificar las exportaciones. Como vimos en el apartado teórico el comercio Intraindustrial puede ayudar a esto último.

A continuación se muestran los resultados de índices de los flujos intra sectoriales. Para ello primeramente se deben hacer unas primeras aclaraciones. Primero se utilizó la base de datos del Sistema de Estadísticas de Centroamérica (SEC) ${ }^{13}$ que esta basado en el SAC, (Sistema Arancelario Centroamericano). El SAC esta basado en ocho dígitos: el primero le corresponde a las secciones, que son 22, el segundo a los capítulos, que son 99, los dos siguientes a partidas contables, el tercer par de dígitos, a subpartidas y los dos últimos a incisos. Para propósitos de este apartado, se utilizo la información desagregada hasta el nivel de capítulos, ya que en las publicaciones consultadas se prevé que la precisión de la medición esta en función de la desagregación de la información.

Se utilizo el Índice de Grubel y Lloyd (GL) ${ }^{14}$, este puede oscilar entre 0 sino hay Intraindustrialidad y 100 si la hay completa, estos valores son extremos. El cuadro No.8, muestra los dos Índices Grubel y Lloyd para cada país con Centroamérica desde 1994 hasta 2002, el cual refleja el porcentaje del total del comercio que es Interindustrial. 
(Cuadro No.8) Índices de Comercio Intraindustrial

\begin{tabular}{|c|c|c|c|c|c|c|c|c|c|}
\hline País & 1994 & 1995 & 1996 & 1997 & 1998 & 1999 & 2000 & 2001 & 2002 \\
\hline Guatemala & $73.45 \%$ & $65.28 \%$ & $58.86 \%$ & $66.92 \%$ & $76.30 \%$ & $62.78 \%$ & $67.33 \%$ & $66.21 \%$ & $68.69 \%$ \\
\hline El Salvador & $59.51 \%$ & $66.25 \%$ & $67.50 \%$ & $66.49 \%$ & $64.78 \%$ & $62.94 \%$ & $65.60 \%$ & $61.52 \%$ & $63.30 \%$ \\
\hline Honduras & $33.83 \%$ & $39.89 \%$ & $34.06 \%$ & $25.32 \%$ & $43.16 \%$ & $41.16 \%$ & $39.60 \%$ & $37.43 \%$ & $43.63 \%$ \\
\hline Nicaragua & $28.29 \%$ & $27.52 \%$ & $23.29 \%$ & $28.42 \%$ & $22.33 \%$ & $23.93 \%$ & $24.84 \%$ & $28.57 \%$ & $34.21 \%$ \\
\hline Costa Rica & $55.76 \%$ & $55.21 \%$ & $52.77 \%$ & $56.98 \%$ & $53.00 \%$ & $50.63 \%$ & $50.93 \%$ & $46.83 \%$ & $45.32 \%$ \\
\hline
\end{tabular}

Fuente: Elaboración propia con datos de la SIECA.

Los resultados no son tan contundentes como los que se esperaban. Sin embargo, en Centroamérica si podemos decir que hay una significativa presencia de comercio intraindustrial.

Para cada país el comercio intraindustrial tiene diferente importancia. Primero, para la economía más grande de Centroamérica ${ }^{15}$, Guatemala, el índice GL es de $68.69 \%$. Para este país, la mayoría de comercio con Centroamérica es bidireccional El 63.30\% del comercio de El Salvador con Centroamérica es de carácter intraindustrial según el índice GL.

Para Honduras, en el año 2002 el Índice GL fue de 43.63\%, Para Nicaragua, el índice para el 2002 fue el menor de la región, fue de un $34.21 \%$. Asimismo, en estas naciones, durante el período analizado se observa una alta volatilidad en el índice.

Y finalmente, para Costa Rica la segunda economía más grande, el comercio Intraindustrial fue el $45.32 \%$ en el 2002.

Esto puede entenderse que en Centroamérica hay países más desarrollados que otros y podemos decir que Honduras y Nicaragua son los que se están quedando atrás. Podemos afirmar también que el comercio Intraindustrial e incluso el comercio intracentroamericano, esta concentrado en el núcleo, Guatemala- El Salvador. No obstante al hablar de Nicaragua y Honduras eso cambia, el comercio Intraindustrial en estas naciones no tiene tanta importancia. Para Costa Rica, el comercio intraindustrial tiene una presencia significativa. 
En el cuadro No. 9 se colocaron los resultados de aplicar el índice de ventajas comparativas reveladas de Balassa ${ }^{16}$ sobre los flujos de comercio entre Centroamérica y el resto del mundo, según las secciones del SAC. Este describe cual es el desenvolvimiento de los sectores exportadores.

Cuadro No. 9 Índices de ventajas reveladas de Balassa

\begin{tabular}{|c|c|c|c|c|c|c|c|c|}
\hline Secciones & 1994 & 1995 & 1996 & 1997 & 1998 & 1999 & $2000^{(P)}$ & $2001^{(P)}$ \\
\hline 1 & 0.578 & 0.620 & 0.605 & 0.467 & 0.422 & 0.358 & 0.330 & 0.248 \\
\hline 2 & 0.581 & 0.650 & 0.372 & 0.620 & 0.639 & 0.329 & 0.625 & 0.447 \\
\hline 3 & -0.551 & -0.598 & -0.257 & -0.296 & -0.254 & -0.202 & -0.196 & -0.292 \\
\hline 4 & 0.176 & 0.173 & 0.186 & 0.158 & 0.105 & -0.027 & -0.091 & -0.099 \\
\hline 5 & -0.908 & -0.884 & -0.161 & -0.762 & -0.807 & -0.156 & -0.721 & -0.821 \\
\hline 6 & -0.707 & -0.683 & -0.493 & -0.650 & -0.629 & -0.491 & -0.584 & -0.653 \\
\hline 7 & -0.588 & -0.635 & -0.872 & -0.612 & -0.622 & -0.846 & -0.610 & -0.605 \\
\hline 8 & 0.136 & 0.075 & 0.214 & 0.135 & 0.182 & 0.391 & 0.259 & 0.199 \\
\hline 9 & 0.424 & 0.403 & 0.303 & 0.391 & 0.302 & 0.288 & 0.231 & 0.106 \\
\hline 10 & -0.738 & -0.746 & -0.675 & -0.661 & -0.702 & -0.685 & -0.727 & -0.639 \\
\hline 11 & -0.151 & -0.152 & -0.134 & -0.026 & -0.127 & -0.157 & -0.120 & -0.093 \\
\hline 12 & -0.115 & -0.240 & -0.325 & -0.220 & -0.239 & -0.543 & -0.402 & -0.494 \\
\hline 13 & -0.528 & -0.522 & -0.353 & -0.494 & -0.541 & -0.306 & -0.485 & -0.477 \\
\hline 14 & 0.302 & 0.319 & 0.522 & 0.342 & 0.299 & 0.475 & 0.245 & 0.310 \\
\hline 15 & -0.728 & -0.713 & -0.586 & -0.669 & -0.675 & -0.581 & -0.557 & -0.626 \\
\hline 16 & -0.910 & -0.873 & -0.683 & -0.680 & -0.526 & -0.474 & -0.351 & -0.576 \\
\hline 17 & -0.986 & -0.963 & -0.930 & -0.961 & -0.973 & -0.952 & -0.938 & -0.938 \\
\hline 18 & -0.926 & -0.715 & -0.842 & -0.623 & -0.869 & $-0-.48$ & -0.403 & -0.127 \\
\hline 19 & -0.911 & -0.998 & -0.946 & -0.996 & -0.862 & -0.723 & -0.979 & -0.831 \\
\hline 20 & -0.435 & -0.292 & -0.235 & -0.260 & -0.357 & -0.791 & -0.500 & -0.485 \\
\hline 21 & 0.487 & 0.561 & 0.762 & -0.804 & -0.932 & -8.174 & -0.937 & -0.642 \\
\hline 22 & 0.937 & 0.961 & 0.718 & 0.444 & -0.393 & -0.703 & 0.212 & -0.445 \\
\hline
\end{tabular}

Fuente: Elaboración propia con datos de la SIECA.

Los resultados no son alentadores. La mayoría de las secciones del SAC presentan un deterioro en el saldo exterior y en sus rendimientos, con respecto al flujo de comercio que se tiene en total. Las secciones 1 y 2 decrecen y de la 3 a la 22 se muestran índices con saldos negativos. A excepción de la 8,9 y la 14. 
La sección 2 es la que presenta mayor valor del índice, su título es: productos del reino vegetal, incluye productos de floricultura, hortalizas, melones, sandias, y café. Se observa una tendencia a la baja, lo que significa pérdida de competitividad.

En la sección 1 valor del índice decrece durante todo el período, se refiere a Animales vivos y productos del reino animal; carnes, pescados, leche, miel, huevos, camarones etc. La sección 9 esta dedicada a manufacturas de Madera, espartería y cestería, durante todo el período el índice pierde valor.

En la sección 8 se contabilizan pieles, cueros, peletería y talabartería. Durante el período tuvo el índice aumento y bajó dos veces, 1996 y 1998. En la sección 14 se ponen las Perlas finas, piedras y metales preciosos y sus manufacturas, el índice aumento del 2000 al 2001, cayó en 1999 y en 1996.

Todas las secciones anteriores poseen índices positivos es decir que todavía tienen ventajas comerciales. Sin embargo la competitividad se deteriora.

La sección 17 es la que muestra el mayor resultado negativo, ésta destinada para la contabilización de material de transporte, entre los cuales podemos encontrar concretamente vehículos y sus repuestos.

Le sigue la sección 19, está designada para los productos de armamento bélico ya la hemos mencionado. Este es un sector importador neto en el que Centroamérica no tiene ninguna ventaja.

La sección 5 se refiere a productos minerales, lo que incluye combustibles minerales donde están los derivados del petróleo como combustible y demás productos metalíferos. En este sector tenemos una desventaja natural.

Las secciones 10 y 21 corresponden a los productos de madera, papel y cartón para reciclar y objetos de arte, están en una posición difícil también.

La sección 15 se refiere a manufacturas de metal como el hierro, cobre, níquel, aluminio, estaño, en la están incluidas herramientas de construcción. En estos productos también tenemos desventajas.

A través de este recorrido, se pone de manifiesto desde una perspectiva bastante general el desequilibrio exterior y una perdida de competitividad de Centroamérica con respecto al mundo. Posiblemente provocada, a 
una profunda internacionalización de las economías aunada con un deterioro de las capacidades exportadoras, en la mayoría de sus sectores.

Desde los argumentos teóricos que se han manejando, surge la reflexión que es difícil imaginar que los bienes de las secciones donde hay ventajas reveladas crecerán en su competitividad, con una envergadura tal, que anule el efecto de la perdida de competitividad de todas las demás exportaciones. Sí podemos imaginar la cantidad de recursos que se moverían hacia esos sectores.

La integración con la teoría de la intraindustrialidad, muestra otra forma de superar esa problemática. El objetivo de largo plazo sería que todos los países compren y vendan toda la gama de productos que les sea posible y las empresas extranjeras queden absorbidas por un mercado ampliado, invirtiendo y deslocalizando sus actividades en cada país. Y así suplir el ingreso necesario para poder importar los bienes que son escasos en Centroamérica por naturaleza, o los bienes en las cales no se tiene ninguna ventaja comparativa como el petróleo.

Por otra parte, como se mencionado en el comercio intraregional hay desequilibrios importantes que deben ser mencionados, por lo cual, se construyo el Índice de Similitud de Distribución de las Exportaciones ${ }^{17}$ y el de las ventajas reveladas de Balassa. El primero varía entre dos extremos: $100 \%$ si tienen una estructura completamente igual y $0 \%$ si es completamente diferente. Por ser demasiados datos, comentaremos solamente los más importantes. Se aplicaron a las 10 posibles combinaciones de flujos de comercio que se realizan entre los cinco países Centroamericanos, con los datos del SEC ordenados por capítulos, desde 1994 al 2002. Los capítulos, son extensos por lo cual se menciona solamente la generalidad de los productos que están destinados a contabilizar.

Cuadro 10 Índices de similitud de distribución de exportaciones de Guatemala con países centroamericanos

\begin{tabular}{|l|c|c|c|c|c|c|c|c|c|}
\hline GUATEMALA & 1994 & 1995 & 1996 & 1997 & 1998 & 1999 & 2000 & 2001 & 2002 \\
\hline El Salvador & $55.90 \%$ & $60.26 \%$ & $61.19 \%$ & $59.89 \%$ & $66.45 \%$ & $58.01 \%$ & $57.06 \%$ & $63.71 \%$ & $52.28 \%$ \\
\hline Honduras & $35.53 \%$ & $33.83 \%$ & $37.33 \%$ & $39.88 \%$ & $38.41 \%$ & $39.90 \%$ & $42.27 \%$ & $46.70 \%$ & $55.47 \%$ \\
\hline Nicaragua & $51.15 \%$ & $48.09 \%$ & $37.91 \%$ & $47.75 \%$ & $44.76 \%$ & $50.61 \%$ & $48.46 \%$ & $53.68 \%$ & $62.09 \%$ \\
\hline Costa Rica & $63.02 \%$ & $61.99 \%$ & $61.79 \%$ & $57.89 \%$ & $58.94 \%$ & $54.18 \%$ & $58.32 \%$ & $57.22 \%$ & $60.52 \%$ \\
\hline
\end{tabular}

Fuente: Elaboración propia con datos de la SIECA. 
En el cuadro No. 10 vemos el Índice de Similitud de Exportaciones para Guatemala. Tiene unos porcentajes bastantes altos y constantes con toda la región.

Con Honduras ha habido un aumento constante de este índice. Lo que quiere decir que a medida pasa el tiempo los sectores hondureños que exportan a Guatemala tiene la misma ponderación con respecto a las exportaciones totales que los sectores guatemaltecos tienen con el total de sus exportaciones hacia Honduras. Las más marcadas similitudes se perciben con Costa Rica y con El Salvador, lo que ha sido más o menos constate en el tiempo.

Para el Índice de Ballassa: Las exportaciones de Guatemala hacia El Salvador tienen las mayores ventajas en los capítulos 1, 6, 7, 8, 12, 13, 24, 38 y 94, los cuales se refieren a animales vivos, productos de floricultura, frutas comestibles, frutos oleaginosos, jugos, tabaco, productos de industrias química, productos de óptica y cinematografía.

El Salvador salio con ventajas en los capítulos 2, 3, 4, 17, 27, 36, 67, 82,78 y 70 , que se refieren a carnes, pescados y crustáceos, leche, azucares, aceites minerales, pólvora explosivos, artículos de plumas artificiales, fundaciones de hierro, plomo y sus manufacturas y vidrió y sus manufacturas.

Las exportaciones de Guatemala hacia Costa Rica tienen las ventajas en los capítulos 8, 11, 24, 33, 34, 52, 63, 58, 64 y 71. Los que se refieren a: frutos comestibles: melones y sandías, productos de malta, almidón, tabaco, aceites, cosméticos, jabones, algodón, tejidos especiales, calzado y perlas finas.

Las ventajas de Costa Rica resultaron en los capítulos 1, 2, 3, 4, 6, 9, $13,18,21,25,41,48,76$ y 85 . Los productos que se organizan acá son: animales, carnes, pescados, leche, floricultura, café, gomas de resina, cacao, sal, azufre, pieles, manufacturas de celulosa, aluminio y sus manufacturas, aparatos eléctricos, aparatos electrónicos de sonido y televisión.

Las ventajas de las exportaciones de Honduras hacia Guatemala surgen en los capítulos $1,2,3,4,35,43,50$ y 55, los que corresponden a los productos siguientes: animales, pescados, leche, carnes, productos de base de almidón, confecciones de peletería, seda y fibras sintéticas.

Y Nicaragua, con los capítulos 1, 2, 3, 4, 37, 44 y 50, los que organizan productos de animales, carnes, leches, pescados, productos fotográficos $y$ cinematográficos, manufacturas de madera y seda. 
Cuadro $\mathrm{N}^{0} 11$ Índices de similitud de distribución de exportaciones de El Salvador con países centroamericanos

\begin{tabular}{|l|c|c|c|c|c|c|c|c|c|}
\hline ELSALVADOR & 1994 & 1995 & 1996 & 1997 & 1998 & 1999 & 2000 & 2001 & 2002 \\
\hline Honduras & $45.75 \%$ & $45.41 \%$ & $48.74 \%$ & $51.37 \%$ & $49.98 \%$ & $46.44 \%$ & $49.98 \%$ & $43.69 \%$ & $61.22 \%$ \\
\hline Nicaragua & $49.47 \%$ & $54.97 \%$ & $46.91 \%$ & $48.06 \%$ & $52.96 \%$ & $47.56 \%$ & $49.91 \%$ & $48.31 \%$ & $65.64 \%$ \\
\hline Costa Rica & $42.68 \%$ & $43.16 \%$ & $44.92 \%$ & $50.18 \%$ & $54.42 \%$ & $49.15 \%$ & $56.62 \%$ & $46.39 \%$ & $58.14 \%$ \\
\hline
\end{tabular}

FUENTE: Elaboración propia con datos de la SIECA

En el cuadro No.11, se muestran los datos del índice de similitud de distribución de exportaciones de El Salvador con respecto a los demás países, menos Guatemala. Se observa que la distribución de las exportaciones entre El Salvador, Honduras y Nicaragua es bastante similar. Esto ha crecido con el tiempo.

En lo que se refiere a las ventajas relativas, Honduras tiene ventajas con respecto a El Salvador en los productos de los capítulos: 3, 5, 10, 12, 24, y 44, que se refieren a productos de la pesca y otros del reino animal, cereales, semillas oleaginosas, tabaco y manufacturas de madera.

Para Nicaragua, las ventajas están en los capítulos, 1, 2, 3, 4, 7, 23, 41, 44 y 69, es decir en los productos siguientes: animales vivos, pescados, carnes y leche, hortalizas, plantas y raíces, manufacturas de Madera y cerámicas.

A Costa Rica le corresponden beneficios en los capítulos 1, 4, 21, 15, $16,32,41,40,70,81,91$ y 96, con los productos siguientes: animales vivos, leche, grasas y aceites animales, extractos tinteros, pieles, manufactura de vidrio y aparatos de relojería.

Para el Salvador le significan ventajas con todos los países en los capítulos $1,11,9,18,15,17,22,28,31,33,51,61,73,58$, y 82 , a los que corresponden los bienes siguientes: animales vivos, productos de molinera, café, cacao, grasas y aceites animales, azúcar, bebidas alcohólicas, productos químicos, abonos, perfumería, lanas, prendas de vestir y herramientas para la construcción. 
Cuadro $\mathrm{N}^{\circ} 12$ Índices de similitud de distribución de exportaciones de Honduras con países centroamericanos

\begin{tabular}{|l|c|c|c|c|c|c|c|c|c|}
\hline HONDURAS & 1994 & 1995 & 1996 & 1997 & 1998 & 1999 & 2000 & 2001 & 2002 \\
\hline Nicaragua & $40.19 \%$ & $55.19 \%$ & $30.13 \%$ & $14.74 \%$ & $29.11 \%$ & $51.99 \%$ & $52.90 \%$ & $65.91 \%$ & $65.77 \%$ \\
\hline Costa Rica & $32.09 \%$ & $42.94 \%$ & $30.59 \%$ & $30.62 \%$ & $42.57 \%$ & $47.67 \%$ & $51.06 \%$ & $46.29 \%$ & $69.10 \%$ \\
\hline
\end{tabular}

Fuente: Elaboración propia con datos de la SIECA

Según el índice de similitud de distribución de exportaciones del cuadro No. 12, Honduras tiene una distribución bastante similar a través de los años con Nicaragua. También se observa como el índice aumenta a través de los años con respecto a Costa Rica. Podemos decir partiendo de todo lo anterior que Nicaragua y Honduras son países que tienen una alta semejaza en la distribución de las exportación del mismo tipo de bienes.

Nicaragua tiene ventajas en los capítulos: 1, 2, 3, 4, 7, 10, 11, 12, 22, $23,28,23,33$, y 49 . Con los productos siguientes: animales, pescados, leche y carnes, hortalizas y raíces, productos de molinería, semillas, bebidas alcohólicas, alimentos para animales y productos químicos.

Honduras tiene beneficios en los capítulos: 15, 16, 19, 20, 31, 36, 14, 49 y 64. En los productos siguientes: grasas y aceites animales, preparaciones de carne, preparaciones de harina, preparaciones de hortalizas, abonos, pólvora o explosivos y calzado.

Se observa, que la única combinación que falta es Nicaragua con Costa Rica, presentada en el cuadro No. 13.

Cuadro $\mathrm{N}^{\circ} 13$ Índices de similitud de distribución de exportaciones de Nicaragua con Costa Rica

\begin{tabular}{|l|c|c|c|c|c|c|c|c|c|}
\hline NICARAGUA & 1994 & 1995 & 1996 & 1997 & 1998 & 1999 & 2000 & 2001 & 2002 \\
\hline Costa Rica & $52.67 \%$ & $43.57 \%$ & $38.82 \%$ & $36.58 \%$ & $41.79 \%$ & $40.79 \%$ & $44.79 \%$ & $51.91 \%$ & $64.87 \%$ \\
\hline
\end{tabular}

Fuente: Elaboración propia con datos de la SIECA

En cuanto a las ventajas relativas, Nicaragua obtiene ventajas en capítulos 4, 5, 48, 46 y 69. En productos como la leche, bienes de comestibles de origen animal, manufacturas de cestería y cerámicas.

Costa Rica tiene ventajas en los capítulos $30,38,37,52,57,73,76$, 82, 87 y 96 en productos farmacéuticos, productos cinematográficos, 
algodón, alfombras, manufacturas de hierro, manufacturas de aluminio, herramientas y accesorios de vehículos.

Finalizando el recorrido a través de estos Índices podemos imaginar al mercado centroamericano segmentado en tres planos: en el primero plano se puede situar a Costa Rica, en el segundo se situarían Guatemala y El Salvador y en el tercero, estuvieran Honduras y Nicaragua. Ya que estos últimos tienen poco comercio Intraindustrial y sus ventajas se contabilizaron en productos que vienen de explotar sus recursos naturales, estos países son los que presentan mayores déficits intraregionales. Entre Guatemala y El Salvador se comercian bienes manufacturados que corresponden a otro nivel de capacidades productivas, con altos niveles de comercio Intraindustrial. Y por ultimó Costa Rica que comercia bienes donde se han utilizado a más profundidad los recursos tecnológicos.

\section{Conclusiones y recomendaciones}

Desde 2003, Centroamérica está realizando políticas de integración de mayor envergadura con los intentos de perfeccionar la unión aduanera. El proceso está acompañado de las negociaciones de un Tratado de Libre Comercio con Estados Unidos.

Esto provoca un debate entre dos vertientes: la liberalización multilateral que está sostenida en su esencia en los argumentos de los efectos desventajosos de la desviación de comercio. Y por otra parte la integración, que en países subdesarrollados se sustenta en las potencialidades que encierra para el desarrollo.

Hoy en día, la integración regional centroamericana es una realidad porque las dos vertientes se la exigen, una para construir el sistema internacional de comercio multilateral en el cual se puede participar solamente en bloques, por lo menos eficazmente. $Y$ la otra porque cada vez es más evidente que el desarrollo económico esta vinculado al tamaño del mercado, incluyendo los efectos dinámicos que con lleva.

Por otra parte, la economia mundial está pasando por una desaceleración económica. El comercio mundial se ha contraído. Estados Unidos tiene un déficit estructural en la cuenta corriente del 5\% del PIB, según datos del FMI, y ha fracasado en su intento de llevar adelante una agenda multilateral mundial ejemplarizado por el fracaso de las rondas del GATT y después con los choques con la Unión Europea en la OMC. 
Ello ha empujado a los Estados Unidos a abandonar los esfuerzos por una liberalización multilateral de comercio y ha entrado en la dinámica de regionalismo en bloques.

Podemos decir que los efectos dinámicos de la integración pueden ser de diferente tipo: unos provienen de las economías de escala, otros provocan una reducción de precios de los productos de monopolios que se rompen con la integración.

Entre estos, el comercio intraindustrial es el que mejor encierra las ventajas para países subdesarrollados siendo un fenómeno que es frecuente entre países desarrollados. Consiste en desmitificar la teoría de la ventaja comparativa, ya que si se comercian bienes semejantes, de forma bidireccional, esas economías empiezan a mejorar su saldo exterior, en el sentido, que lo que se importa también se exporta y la competencia se ve favorecida.

Al criticar la teoría de la ventaja comparativa, se pone en entredicho el modelo de Heckscher Ohlin, el cual detalla los términos de política económica que llevan a la concentración de todos los recursos de los países hacia la producción de unos bienes en específico, en el caso de algunos países subdesarrollados del área tropical a exportar monocultivistamente productos como el café. En esos productos se tenía una ventaja comparativa por poseer relativamente una dotación de factores de producción mayor, como la tierra, el clima y la mano de obra.

Para corregir el déficit de la balanza comercial, las economías deben de ser lo más completas que le sea posible en la gama de productos y servicios, solamente así se explotarían los beneficios de la competencia y solo así se podrá cargar con el peso de los bienes que no se pueden producir por algunos países como el petróleo y sus derivados. El comercio Intraindustrial es un mecanismo que colabora en este sentido.

También así se crea economía en el sentido del "multiplicador" con más empresas, trabajadores y consumidores correspondiéndose con crecimiento, empleo y bienestar, incluyendo al sector exterior y de que mejor manera que haciendo esos mercados exteriores interiores.

La integración económica no es una panacea tiene sus dificultades y perjuicios, por eso debe estar acompañada inexorablemente de Instituciones que la conduzcan y propicien mecanismos de compensación a los perdedores. 
Mediante el análisis de datos estadísticos trabajados con el concepto de consumo aparente se concluyó que en Centroamérica hay una propensión mayor a creár comercio del exterior hacia el interior que en el interior mismo.

El Coeficiente Importaciones intraregionales/Consumo Aparente ha crecido un $0.95 \%$ y el coeficiente Importaciones extraregionales/ Consumo Aparente ha crecido $2.30 \%$.

Se observó como en los años de mayor desaceleración económica mundial ha correspondido un mayor crecimiento del comercio intraregional intraindustrial. Por lo cual podemos concluir que en una proporción mínima, la integración sirve de atenuante o amortiguadora de choques externos, en ocasiones de volatilidad de los mercados internacionales.

$\mathrm{Al}$ analizar con el índice de Ballassa los flujos de comercio entre Centroamérica y el resto del mundo, a través de las 22 secciones del SAC. Los resultados no son alentadores, la mayoría de las secciones del SAC presentan un deterioro en el saldo exterior con respecto al flujo de comercio que se tiene en total. Las secciones 1 y 2 decrecen y de la 3 a la 22 se muestra un Índice con saldo negativo. A excepción de las secciones 8,9 y 14. Lo cual es causado por la apertura cada vez más grande de sus economías aunada con un deterioro sistemático de la competitividad de las exportaciones, exportando bienes que son de menor valor que los productos que importa.

Para saber si la integración centroamericana puede mejorar lo anterior se construyeron los índices de Grubel y Lloyd. Se concluye que en el comercio Intracentroamericano hay una presencia importante aunque no abrumadora de Intraindustrialidad, en el 2002 significo un $68.69 \%$ para Guatemala, un $63.30 \%$ para El Salvador, un $43.63 \%$ para Honduras, $34.21 \%$ para Nicaragua y $45.32 \%$.

La intraindustrialidad es un factor importante para el comercio Centroamericano y posiblemente desempeñe un papel más importante en el futuro, ya que va acompañando al proceso. Podemos ver como entre Guatemala y El Salvador hay una fuerte presencia de Intraindustrialidad y a manera de ejemplo, pensemos que son estos dos países los que están iniciando, más rápidamente los adelantos para la unión aduanera y constituyen el núcleo del comercio intracentroamericano. 
De esta manera podemos ver como la Integración Centroamericana es bastante pequeña, pero desempeña un rol importante por sus beneficios, como ser atenuante de los choques externos, lo que contribuye a mejorar los déficits comerciales.

Todo lo anterior nos lleva al hecho que el comercio intracentroamericano es de mayor valor agregado que el comercio con el resto del mundo, aunque esté sea de mayor volumen, y el comercio intraindustrial, está más concentrado en el comercio intracentroamericano. Por lo que, para los países subdesarrollados su integración es una necesidad imperiosa para lograr mejoras en su desarrollo.

Sin embargo, el mercado centroamericano, en lugar de estar integrado está segmentado en tres planos: en el primero, se puede situar a Costa Rica; en el segundo, se situarían Guatemala y El Salvador y en el tercero, estarían Honduras y Nicaragua, ya que el nivel de comercio intraindustrial es muy bajo y sus ventajas se materializan en productos que vienen de explotar sus recursos naturales, estos países son los que presentan mayores déficits intraregionales. Entre Guatemala y El Salvador se comercian bienes manufacturados que corresponden a otro nivel de capacidades productivas, y están acompañados de los niveles mas altos de comercio intraindustrial. Y Costa Rica que comercia bienes donde se han utilizado a más profundidad los recursos tecnológicos.

La integración es una utopía, pero es el escenario más idóneo para participar en la economía mundial. En el discurso, siempre es halagada, tanto por la derecha como por la izquierda, pero no se realizan las políticas necesarias para crearla y conducirla.

Sírvase de ejemplo, que hoy en día y después las negociaciones del Plan de Acción para la Unión Aduanera, esté no se concluyó en el plazo propuesto.

Solamente a través de la integración económica, Centroamérica será tomada en cuenta en la globalización actual.

Ahora bien, corresponde a nosotros los centroamericanos que este camino responda más a los intereses y beneficios, de y para los centroamericanos y no se disperse por causa de los adelantos de la regionalización multilateral global, ya que se perdería un motor poderoso para diversificar el comercio en competencia simétrica. 


\section{BiBLIOGRAFÍA}

Andic, de S. y S. Teitel, "Integración Económica: Selección" Fondo de Cultura Económica, México 1977.

Banco Interamericano de Desarrollo, "Nuevo regionalismo" V. ADR International, Virginia, agosto de 1998.

Balassa, Bela "Teoría de la Integración Económica", EE.UU, Fondo de Cultura Económica, Illinois, 1964.

Bhagwati, Jagdish "Writing on Internacional Economics", V.N. Balasumbramanyam, Oxford University Press, New York and london, 1997.

Bhagwati, Jagdish, "Free Trade Today", Princeton University Press, Princeton and Oxford, New York, 2002.

Bulmer Thomas, Victor "Regional Integration in Latin América and the Caribbean; The Policy Economy of the Caribbean", Insitute Of Latin Amercian Studies, Universidad de Londres, Inglaterra, 2001.

Cabrera Melgar, Óscar, "Factores explicativos de la competitividad industrial en los paises del mercado común centroamericano; un enfoque de costes y precios". Primera jornada de investigación de REDIBASEN, 2002.

Cáceres, Luis René "La Integración de Centroamérica: promesa y reto vigente”. Banco centroamericano de Integración Económica, Honduras, 30 de junio de 2002.

Caldentey del Pozo, Pedro, "El desarrollo económico de Centroamérica en el marco de la integración regional". Banco Centroamericano de Integración Económica, octubre de 2000.

Ganlduf, Joseph Maria (coordinador), "Economía de la Unión Europea". Civitas Ediciones, Madrid, 2002.

Calvo Hornero Antonia, "Integración Económica y Regionalismo; Principales Acuerdos comerciales". Editorial de Estudios Ramón Araces, s.a. Madrid, España, 1994.

García Grande, María José (coordinadora) y Carmen Maria Fernández Otho. "Economia europea, crecimiento, integración y transformación sectorial”, Civitas Ediciones, Madrid, 2000. 
Cechinni, Paolo, "Integración Económica: contenido, eficacia y política". Seminario sobre integración Centroamérica hoy, San Salvador, febrero 2003.

Gonzáles Fernández, Sara, "Economia internacional, introducción a la teoría del comercio internacional", Ediciones Pirámide, Anaya, Madrid, 2002.

González, Jaime Requeijo, Economia Mundial; un análisis entre dos siglos, Mc Graw Hill, Madrid, 1995.

Granados, Jaime "La integración comercial centroamericana: un marco interactivo y cursos de acción plausible". Banco Interamericano de Desarrollo, Departamento de integración y programas regionales, Instituto para la Integración de América Latina y del Caribe (INTAL). Buenos Aires, Argentina, 2001.

Guillen Romo, Héctor "De la integración cepalina a la integración neoliberal en América Latina", Universidad de París, París, 2000.

Gutiérrez Luna, Carlos E. "Informe de Avances de la Integración Centroamérica", Secretaría. General de Integración Centroamericana, San Salvador, Julio de 2003.

De la Rosa, Dean A. "Regional Integration Arrangements: Static Economic Theory, Quantitative Findings, and Police Guidelines”, ADR international, Virginia, agosto de 1998.

French-Davis Ricardo, "Economia Internacional"; Fondo de Cultura Económica, México, 1979.

Ibáñez, Joseph, "El nuevo regionalismo latinoamericano en los años noventa", Presentado en la XVIII Jornada de la Asociación Española de Profesores de Derecho internacional "Ibero América ante los procesos de integración", Universidad Pompeu Fabra, Cáceres, España del 23 al 25 de septiembre de 1999.

Instituto de Estudios económicos de Madrid, "Hacia dónde va Europa", Revista del Instituto de Estudios Económicos, No 3, Madrid, 2001.

Instituto para la integración de América Latina y del Caribe, INTAL. "Informe Centroamericano 2000", Departamento de integración y programas regionales, Buenos Aires, 2000. 
Jeroen Hiloopen, Charles Van "On The Empirical Distribution of the Balassa Index", Marrewikj”. European Research Workshop on International Trade, Bruselas, febrero de 2000.

Jovanovic, Miroslav N., "Internacional Economic Integration”, Routledge, Londres, 1992.

Krugman, Paul R. y Maurice Obstfelf "Economía Internacional”, Mc Graw Hill/ Interamericana de España, Madrid 1995

Lizano F. Eduardo "La Integración Económica", Fondo de Cultura Económica, México, 1975.

Maudos, Joaquín, José Pastor y Lorenzo Serrano "Economic integration, efficiency and economic growth, the European Union experience", Applied Economic Letters, 1999.

Perroux, François, "¿Quién integra? ¿En beneficio de quien se realiza la integración?”, Revista de Integración No. 1, noviembre de 1967, París.

Reig, Ernest y Cecilio Tamarit, "Economia de la Unión Europea", Universidad de Valencia, 2000.

Robson, Peter "The Economic of International Integration", Routledge, Londres, 1993.

Rueda Junquera, Fernando, "La reactivación del mercado común centroamericano", Universidad de Burgos, 1999.

Ruega, Santos M, Maria Isabel Heredero y Gerardo Fuji (coordinadores), "Europa e Iberoamérica: dos escenarios de Integración Económica", Editorial Parteluz, Colección Ariadna, Madrid, 1998.

Sanahuja, José Antonio y José Ángel Sotillo (Coords) "Integración y desarrollo en Centroamérica. Más allá del libre comercio", Instituto universitario de desarrollo y cooperación de la Universidad Complutense, Los Libros de la Cátara, Madrid 1998.

Secretaría de Integración Económica Centroamericana. "Informe Económico regional 2002”, Guatemala, 2002.

Secretaría de Integración Económica Centroamericana "Series estadísticas seleccionadas de Centroamérica 32”, Guatemala, junio de 2003. 
Tamarit, Cecilio. "La política comercial entre bloques regionales: Integración versus Multilateralismo". Papeles de Economía Española, Valencia, 1996.

Tugores Ques, Juan "Economía internacional e Integración Económica”, Barcelona Universidad de Barcelona, Mc Graw Hill, España, 1995.

Wionczek, Miguel "Integración de la América Latina Experiencias y perspectivas”, Fondo de Cultura Económica, México, 1964.

Sitios Web:

- wrerw.bcie.org

- wererw.intal.com

- wrere.incae.com

- wrerw.iadb.com

- wrerw.redibasen.bcr.gb

- wrerw.sgsica.org

- wrerw.sieca.org

- wrere.uctad.org

\section{NOTAS}

1 Sara González Fernández, "Economia internacional, Introducción a la teoría del comercio internacional", Ediciones Pirámide, grupo Anaya S.A. Madrid, 2002.

2 Ese es el titulo como se le conoce a la propuesta de la CEPAL elaborada para la integración económica de los países de Latinoamérica. Fue promulgada en el documento, "Transformación productiva con equidad de la CEPAL" (1990) y "Equidad y transformación Productiva: Un Enfoque Integrado" (1992).

3 Esta clasificación fue tomada de "Economía internacional, Introducción a la teoría del comercio internacional".

4 Selección de S. Andic y S. Teitel, Integración "Económica”

5 François Perroux, “¿Quien integra? ¿̇E beneficio de quien se realiza la integracion?”, Revista de integración No. 1, Noviembre de 1967, Paris.

6 La evidencia empírica es presentada en el siguiente apartado.

7 Miroslav Jovanovic, "Internacional Economic integration". 
8 Bulmer Thomas,,Victor "Regional Integration in Latin América and the Caribbean; The Policy Economy of the Caribbean".

9 Ver Fernando Rueda Júnquera, "La reactivación del mercado común centroamericano".

10 Datos de la SIECA.

11 Lo anterior puede escribirse como: $1=\mathrm{P}-\mathrm{X} / \mathrm{CA}+\mathrm{Mi} / \mathrm{CA}+\mathrm{Me} / \mathrm{CA}$. Los cambios en cada proporción están asociados a los procesos de integración desde una perspectiva estática o de corto plazo. El coeficiente P-X/ Consumo Aparente muestra el grado en que la producción interna abastece a la demanda interna, una disminución de este coeficiente expresaría la existencia de creación de comercio. Un aumento del coeficiente $\mathrm{Mi} / \mathrm{CA}$, significa que esa creación de comercio se realiza pero internamente, un aumento $\mathrm{Me} / \mathrm{CA}$ es el resultado de creación de comercio pero externa. El coeficiente entre $\mathrm{Mi} / \mathrm{Me}$ permite observar cual creación de comercio prevalece, interna o externa.

12 Ídem.

13 http://www.sieca.org.gt/SIECA.htm

14 Se construye de la siguiente manera:

$$
\mathrm{ICIi}=\frac{\text { Xit }+ \text { Mit }-(\text { Xit }- \text { Mit })}{\text { Xit }+ \text { Mit }}=\frac{1-(\text { Xit }- \text { Mit })}{\text { Xit }+ \text { Mit }}
$$

Donde "Xit" es el valor de las exportaciones del sector " $i$ " de un país al bloque comercial y "Mit" es el valor de las importaciones de sector "i" procedentes de los socios comerciales. Al Multiplicar por 100 se obtienen porcentajes. Para realizar la medición total, se utilizó: $\left[1-\left(\left(\sum i \mid \text { Xit }- \text { Mid }\right) /\left(\left(\sum i \mid X i t+\text { Mit } \mid\right)\right)\right]^{*} 100\right.$. Según los documentos consultados es necesario utilizar un nivel desagregación considerable.

15 El PIB de Guatemala significa el 37\% del PIB Centroamericano según datos de la SIECA.

$16 \quad \mathrm{IVCR}=(\mathrm{Xij}-\mathrm{Mij}) / \mathrm{Xij}+\mathrm{Mij}$. Compara el saldo comercial del sector con respecto al total de las exportaciones y las importaciones. Oscila entre +1 para los sectores que son netamente exportadores y -1 para los sectores que son netamente importadores.

17 La forma del indicador es: I $a, b=\left(1-\mid\left(\sum\right.\right.$ Sia- Sib $\left.) \mid / 2\right) * 100$. Siendo "S" la representación de la participación de cada una de las ramas de actividades productivas en el total de las exportaciones y A y B son dos países cualquiera. 